\title{
Improving Fab' fragment retention in an autonucleolytic Escherichia coli strain by swapping periplasmic nuclease translocation signal from OmpA to DsbA
}

\author{
Desmond M. Schofield • Ernestas Sirka • Eli Keshavarz-Moore • \\ John M. Ward • Darren N. Nesbeth $(\mathbb{D}$
}

Received: 28 June 2017 / Accepted: 22 August 2017/Published online: 5 September 2017

(C) The Author(s) 2017. This article is an open access publication

\begin{abstract}
Objectives To reduce unwanted Fab' leakage from an autonucleolytic Escherichia coli strain, which coexpresses OmpA-signalled Staphylococcal nuclease and Fab' fragment in the periplasm, by substituting in Serratial nuclease and the DsbA periplasm translocation signal as alternatives.

Results We attempted to genetically fuse a nuclease from Serratia marcescens to the OmpA signal peptide but plasmid construction failed, possibly due to toxicity of the resultant nuclease. Combining Serratial nuclease to the DsbA signal peptide was successful. The strain coexpressing this nuclease and periplasmic Fab' grew in complex media and exhibited nuclease activity detectable by DNAse agar plate but its growth in defined medium was retarded. Fab' coexpression with Staphylococcal nuclease fused to the DsbA signal peptide resulted in cells exhibiting nuclease activity and growth in defined medium. In cultivation to high cell density in a 51 bioreactor, DsbA-fused Staphylococcal nuclease co-
\end{abstract}

D. M. Schofield · E. Keshavarz-Moore

J. M. Ward - D. N. Nesbeth $(\square)$

Department of Biochemical Engineering, University

College London, Bernard Katz Building,

London WC1E 6BT, UK

e-mail: d.nesbeth@ucl.ac.uk

E. Sirka

Centre for Translational Omics, UCL Institute of Child Health \& Great Ormond Street Hospital, 30 Guilford

Street, London WC1N 1EH, UK expression coincided with reduced Fab' leakage relative to the original autonucleolytic Fab' strain with OmpAfused staphylococcal nuclease.

Conclusions We successfully rescued Fab' leakage back to acceptable levels and established a basis for future investigation of the linkage between periplasmic nuclease expression and leakage of co-expressed periplasmic Fab' fragment to the surrounding growth media.

Keywords Autonucleolytic - Bioprocess · Fab' fragment $\cdot$ Leakage $\cdot$ Nuclease $\cdot$ Periplasm

\section{Introduction}

Approaching half of all global blockbuster drugs are currently antibody-based recombinant proteins, a growing number of which are Fab' antibody fragments. When expressed in Escherichia coli, genetically-appended peptide signals are commonly used to direct translocation of Fab' fragment heavy and light chains to the oxidising environment of the periplasmic space where they can form disulphide bonded heterodimers (Ukkonen et al. 2013). Balasundaram et al. (2009) engineered E. coli so that a commercial anticancer Fab' fragment (UCB Celltech UK, Slough, UK) was co-expressed with recombinant Staphylococcal nuclease (Fig. 1) to generate an autonucleolytic Fab' production strain, termed 'Fab' Nuc' previously and 'OSAFab' in this study. 
In the OSAFab strain, both Fab' and nuclease were genetically fused to an OmpA periplasmic translocation peptide sequence and their transcription was controlled by $P_{\text {tac }}$ promoters (de Boer et al. 1983). Cytoplasmic nuclease expression is, however, lethal in E. coli (Ahrenholtz et al. 1994) but in the OSAFab strain periplasmic localisation safely sequesters the nuclease from the host genome, enabling normal cell growth. The E. coli OmpA periplasm translocation signal directs transport to the periplasmic space via the general secretion (SEC) route (Pugsley 1993). Native E. coli proteins translocated by the SEC-route are understood to be translated in the cytosol where they reside briefly before post-translational translocation to the periplasmic space via the SEC pore complex (Pugsley 1993). Upon homogenisation of the OSAFab E. coli strain the Staphylococcal nuclease gained access to and degraded host DNA, decreasing the viscosity of the bioprocess stream and improving its clarification performance.

One unwanted property of the Balasundaram et al. (2009) OSAFab strain, relative to the parental Fab strain without nuclease, was an increased propensity for leakage of Fab' fragment to the growth medium during cultivation to high cell density (reported by Nesbeth et al. 2012). This observation suggested the conclusion that, directly or indirectly, the co-expression of nuclease resulted in the increased level of Fab'

(A)
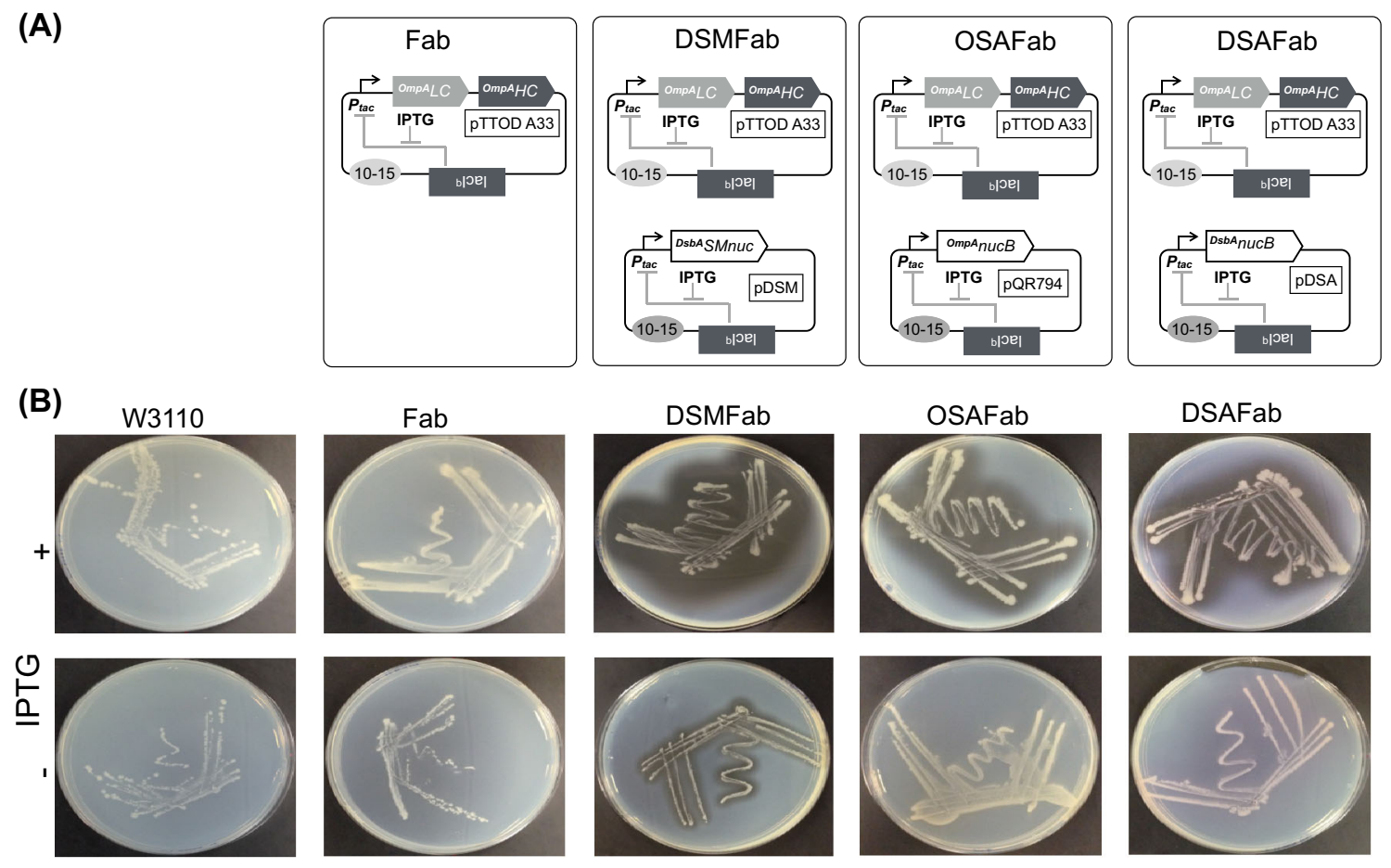

Fig. 1 Strains in this study and their nuclease activity. a From left, the Fab strain harbours only the plasmid pTTOD-A33 with p15A origin of replication (ori) directing a copy number of 10-15 replicons per cell (grey oval). A copy of the lacIq gene encodes expression of lacI that represses the $P_{t a c}$ promoter unless IPTG is present. ORFs encoding Fab' light and heavy chains fused to the OmpA periplasm translocation signal, ${ }^{O m p A} L C$ and ${ }^{O m p A} H C$ are under the control of a single $P_{t a c}$ promoter within a dicistronic expression cassette. The DSMFab strain harbours both the plasmids pTTOD-A33 and pDSM, which has a compatible RSF1010 ori that directs replication of 10-15 copies per cell (grey oval). An ORF encoding $S$. marcescens nuclease nuclease fused to the DsbA signal ( ${ }^{\mathrm{DsbA}} \mathrm{SMnuc}$ ) is under control of the $P_{\text {tac }}$ promoter. A copy of the lacIq gene in pDSM also coordinates IPTG-inducible expression of ${ }^{\text {DsbA }}$ SMnuc from the $P_{t a c}$ promoter. The OSAFab strain harbours pTTOD-A33 and pQR794, which encodes the $S$. aures nucB nuclease fused to the OmpA signal ( ${ }^{\mathrm{OmpA}}{ }_{\text {nucB }}$ ) under control of the $P_{t a c}$ promoter. The DSAFab strain harbours pTTOD-A33 and pDSA, which encodes the $S$. aureus nucB nuclease fused to the DsbA signal ( ${ }^{\mathrm{DsbA}}$ nucB) under control of the $P_{t a c}$ promoter. b Unmodified W3110 cells and the Fab, DSMFab, OSAFab and DSAFab strains were streaked onto DNAse agar plates with (+) and without (-) IPTG present. After overnight incubation plates were flooded with $2 \mathrm{M} \mathrm{HCl}$ and photos taken of the resultant cloudy pattern of DNA precipitation. Clear halos indicate nuclease activity 
leakage, by an as yet unknown mechanism. The intent of the study reported here was to test the hypothesis that, as well as nuclease presence, also the type of nuclease and the type of periplasm translocation signal peptide may also be factors that impact Fab' leakage.

We chose the DsbA signal as an alternative to OmpA. The E. coli DsbA signal (Luirink and Dobberstein 1994) directs translocation via the signal recognition particle (SRP) route in which translation of nascent polypeptides is paused by SRP binding, to form an SRP-ribosome nascent chain (RNC) complex, followed by migration to the FtsY receptor element of the SecYEG pore where translation re-starts concurrently with translocation to the periplasmic space (Avdeeva et al. 2002; Park et al. 2014; Yosef et al. 2010). This contrasts with translocation via OmpA, in which nascent polypeptides are predicted to reside in the cytoplasm prior to translocation (Movva et al. 1980). We reasoned that the more divergent our choice of alternative signal was, in terms of translocation mechanism, the greater the likelihood of observing an impact on strain phenotype.

As an alternative to Staphylococcal nuclease we chose the nuclease of Serratia marcescens which is widely utilised commercially as Benzonase (Ball et al. 1987). We had previously compared the effectiveness of exogenously added Benzonase versus cellularly expressed Staphylococcal nuclease for clearing DNA from process streams (Balasundaram et al. 2009). As such we were interested to take the next logical step and test whether cellularly expressed Benzonase impacted strain performance and resulted in nuclease activity.

To test the hypothesis that nuclease and signal peptide choice can impact Fab' leakage, we attempted to make, and measure Fab' leakage in, three new strains (two of which are illustrated in Fig. 1). Attempts were made to construct E. coli strains in which the following nucleases would be co-expressed with a periplasmic Fab' fragment: Staphylococcal nuclease fused to the DsbA signal in the strain, 'DSAFab', Serratial nuclease fused to the OmpA signal in 'OSMFab' and Serratial nuclease fused to the DsbA signal in 'DSMFab'.

\section{Materials and methods}

All chemicals were purchased from Sigma unless stated otherwise, and were of analytical grade.
Plasmid construction

Figure 1 sets out the relevant genes present in each plasmid. DNA encoding Staphylococcus aureus nuclease fused to the DsbA secretion signal was provided by Eurogentec (Liege, Belgium) in a pUC57 vector then subcloned into pMMB67EH (Furste et al. 1986) between EcoRI and PstI restriction sites. DNA encoding $S$. marcescens nuclease was amplified from locus M19495 (GenBank) in genomic DNA (Bergkessel and Guthrie 2013) using a forward primer designed to anneal downstream of the predicted $S$. marcescens secretion signal and introduce an in-frame HindIII site (underlined), CGAAGCTTGGACACG CTCGAATCCATCGACAACTGCGCGG, and a reverse primer designed to introduce an EcoRI site (underlined) downstream of the stop codon, CGAAT TCAGTTTTTGCAGCCCATCAACTCCGGCAGAA CGCCCGG. Attempts were made to subclone this fragment into a plasmid encoding an OmpA secretion signal with an in-frame HindIII site positioned at the final codon of the signal. The $S$. marcescens nuclease fragment was successfully ligated downstream of a DNA fragment encoding the DsbA signal with an inframe HindIII site positioned at the final codon sequence before being subcloned into pMMB67EH. pTTOD A33 encoding Fab' fragment was donated by UCB Celltech and pQR794, encoding $S$. aureus nuclease fused to the OmpA secretion signal, was constructed as previously described (Nesbeth et al. 2012). Bacterial cell transformations were performed using standard molecular biology techniques.

Plate assay of nuclease activity

DNase agar plates were flooded with $2 \mathrm{M} \mathrm{HCl}$ to form a cloudy DNA precipitate after overnight growth. Nuclease activity was evidenced by precipitate-free zones of clearing around colonies (Cooke et al. 2003).

Shake-flask cultivation

$20 \mu \mathrm{l}$ of a working cell bank glycerol stock was used to inoculate $200 \mathrm{ml}$ lysogeny broth in a 11 shake flask. It was grown at $37{ }^{\circ} \mathrm{C}$ with shaking at $250 \mathrm{rpm}$. For defined media cultivation, $40 \mathrm{ml}$ of this culture was taken when $\mathrm{OD}_{600}$ reached 1 , and used to inoculate $360 \mathrm{ml}$ modified defined media. This modified defined medium ( $\mathrm{Li}$ et al. 2012) contained $5.2 \mathrm{~g}\left(\mathrm{NH}_{4}\right)_{2} \mathrm{SO}_{4}$ 
$\mathrm{l}^{-1}, 4.4 \mathrm{~g} \mathrm{NaH}_{2} \mathrm{PO}_{4} \cdot \mathrm{H}_{2} \mathrm{O} 1^{-1}, 3.4 \mathrm{~g} \mathrm{Na}_{2} \mathrm{HPO}_{4} \mathrm{l}^{-1}$, $4.03 \mathrm{~g} \mathrm{KCl}^{-1}, 1.04 \mathrm{~g} \mathrm{MgSO}_{4} \cdot 7 \mathrm{H}_{2} \mathrm{Ol}^{-1}, 4.16 \mathrm{~g}$ citric acid monohydrate $\mathrm{l}^{-1}, 0.25 \mathrm{~g} \mathrm{CaCl}_{2} \cdot 2 \mathrm{H}_{2} \mathrm{O} \mathrm{l}^{-1}, 112 \mathrm{~g}$ anhydrous glycerol $1^{-1}$ and $1 \%(\mathrm{v} / \mathrm{v})$ trace elements solution. The trace elements solution consisted of $104 \mathrm{~g} \mathrm{l}^{-1}$ citric acid monohydrate, $5.22 \mathrm{~g} \mathrm{l}^{-1} \mathrm{CaCl}_{2 \text { - }}$ $2 \mathrm{H}_{2} \mathrm{O}, 2.06 \mathrm{~g} \mathrm{l}^{-1} \mathrm{ZnSO}_{4} \cdot 7 \mathrm{H}_{2} \mathrm{O}, 2.72 \mathrm{~g}^{-1} \mathrm{MnSO}_{4}$.4$\mathrm{H}_{2} \mathrm{O}, 0.81 \mathrm{~g} \mathrm{l}^{-1} \mathrm{CuSO}_{4} \cdot 5 \mathrm{H}_{2} \mathrm{O}, 0.42 \mathrm{~g} \mathrm{l}^{-1} \mathrm{CoSO}_{4}$. $7 \mathrm{H}_{2} \mathrm{O}, 10.06 \mathrm{~g} \mathrm{l}^{-1} \mathrm{FeCl}_{3} \cdot 6 \mathrm{H}_{2} \mathrm{O}, 0.03 \mathrm{~g} \mathrm{l}^{-1} \mathrm{H}_{3} \mathrm{BO}_{3}$, and $0.02 \mathrm{~g} \mathrm{l}^{-1} \mathrm{Na}_{2} \mathrm{MoO}_{4} \cdot 2 \mathrm{H}_{2} \mathrm{O}$. The medium $\mathrm{pH}$ was adjusted to 6.95 with $15 \%(\mathrm{w} / \mathrm{v}) \mathrm{NH}_{4} \mathrm{OH}$. This defined media culture was then grown at $30{ }^{\circ} \mathrm{C}, 200 \mathrm{RPM}$ orbital shaking.

\section{Bioreactor cultivation}

$400 \mathrm{ml}$ defined media culture from the shake cultivation described above was inoculated into 4.51 of the same modified defined media as above in a New Brunswick BioFlo 1107.51 bioreactor. 40:60 $\mathrm{O}_{2} / \mathrm{N}_{2}$ gas blending was used when necessary to maintain dissolved $\mathrm{O}_{2}$ at $30 \% .15 \%(\mathrm{w} / \mathrm{v}) \mathrm{NH}_{4} \mathrm{OH}$ and $20 \%$ (v/ v) $\mathrm{H}_{2} \mathrm{SO}_{4}$ were used to maintain $\mathrm{pH}$ at 6.95 . The culture was maintained at $30^{\circ} \mathrm{C}$ for $\sim 32 \mathrm{~h}$. After approx. $36 \mathrm{~h}$ post-inoculation the culture temperature was reduced to $25{ }^{\circ} \mathrm{C}$, glycerol fed to the fermenter as described by Perez-Pardo et al. (2011) and Fab' production induced by addition of IPTG. Samples were stored overnight $(16-20 \mathrm{~h})$ at $-20{ }^{\circ} \mathrm{C}$ before further experimentation. For dry cell weight determination, supernatant was removed and pellet dried in an oven until constant weight measured, typically after $24 \mathrm{~h}$ drying time.

Fab' fragment extraction and assay

Total Fab' was extracted from culture samples by transferring $1.5 \mathrm{ml}$ samples to capped borosilicate glass tubes for complete cell disruption by adaptive focused acoustics (AFA) as described by Nesbeth et al. (2012). Briefly, glass sample tubes were submerged in an $8{ }^{\circ} \mathrm{C}\left( \pm 4{ }^{\circ} \mathrm{C}\right)$ degassed water bath and subjected to acoustic radiation of $85 \mathrm{~W}$ intensity by an acoustic energy 'burst' consisting of 500 active energy cycles and 2000 'off' cycles. The disrupted sample was centrifuged for $20 \mathrm{~min}$ at $\sim 10,000 \times \mathrm{g}$ at $15^{\circ} \mathrm{C}$ to remove cell debris. Supernatant was filtered through a $0.22 \mu \mathrm{M}$ syringe and transferred to $2 \mathrm{ml}$ crimp-top vials fitted with $0.1 \mathrm{ml}$ inserts (VWR International
Limited, Leicester, UK). Growth medium samples were prepared by centrifuging $1.5 \mathrm{ml}$ broth samples for $10 \mathrm{~min}$ (omitting disruption steps) and retaining the supernatant to be processed as described above.

Quantitation of Fab' levels

Fab' was quantified using a $1 \mathrm{ml}$ capacity protein $\mathrm{G}$ Hi-Trap column (G. E. Healthcare) in a HPLC as described by Nesbeth et al. (2012). Purified Fab' standards of known concentration were generated in the same manner as previous studies by GarcíaArrazola et al. (2005) in which ELISA was used for quantitation. Fab' was immobilised from samples with packed bed Protein A affinity chromatography using an AKTAprime system (Amersham Biosciences UK Ltd., UK) and an XK50 column $(50 \mathrm{~mm} \times 70 \mathrm{~mm}$, $50 \mathrm{ml}$ column volume) packed with Protein A Sepharose 4 Fast Flow matrix (both from GE Healthcare). An operating flow rate of $35 \mathrm{ml} \mathrm{min}^{-1}$ was used throughout. Glycine/glycinate was added to the column to $1 \mathrm{M}$ ( $\mathrm{pH} 7.5$ ). The column was then equilibrated with 15 column volumes of equilibration buffer (1 M glycine, pH 8). Fab' elution was performed using a method described previously by Bowering et al. (2002). Briefly, Fab' fractions were pooled and buffer-exchanged into storage buffer (100 mM sodium acetate, $125 \mathrm{mM} \mathrm{NaCl}, 0.02 \% \mathrm{w} / \mathrm{v}$ sodium azide, $\mathrm{pH}$ 5.5) using a stirred ultrafiltration cell 8400 (Amicon) with a $20 \mathrm{kDa}$ cut-off Ultracel YM regenerated cellulose membrane (Millipore). Purified Fab' levels were calibrated using previous purified batches as reference. Historically, previous batches of purified Fab' have ultimately been calibrated against batches measured by ELISA. The research-validated (Felinger and Guiochon 2001) software package 'Chemstation' (Agilent technical manual G207091126) was used to measure the $220 \mathrm{~nm}$ peak area to quantify Fab'.

\section{Results and discussion}

Serratial nuclease expression in E. coli impacts cell viability

We attempted construction of a plasmid encoding a Serratial nuclease fused to the OmpA signal controlled 
by the $P_{t a c}$ promoter. None of our approaches were able to yield cells harbouring the desired construct. A control plasmid encoding the Serratial nuclease open reading frame with no promoter upstream was readily constructed and propagated in E. coli. This suggests the Serratial nuclease coding sequence itself is not toxic to E. coli and that it is the expressed nuclease that is responsible for cytotoxicity. Serratial nuclease expression in E. coli is non-lethal (Ball et al. 1987; Biedermann et al. 1989, 1990; Friedhoff et al. 1994) if the native secretion signal was present and lethal (Ahrenholtz et al. 1994; Li and Wu 2009) or if there was no secretion signal at all. Consideration of the previous reports, and our own observation that Serratial nuclease fused to OmpA was lethal to cells, led us to conclude that the OmpA signal was non-functional when fused to Serratial nuclease and that this resulted in toxicity.

Serratial nuclease expression in the E. coli periplasm impacts cell growth

Serratial nuclease was fused to the DsbA signal (Schierle et al. 2003) in the plasmid, pDSM, as was Staphylococcal nuclease in the plasmid, pDSA (Fig. 1a). The previously constructed plasmid, pQR794 (Nesbeth et al. 2012), encoded Staphylococcal nuclease fused to the OmpA signal. The nuclease expression plasmids and pTTOD-A33 were used to successfully generate four strains; the Fab strain encoding Fab' fragment only, the OSAFab strain encoding Fab' and OmpA-signalled Staphylococcal nuclease, the DSAFab strain encoding Fab' and DsbAsignalled Staphylococcal nuclease and the DSMFab strain encoding Fab' fragment and DsbA-signalled Serratial nuclease (Fig. 1a).

We tested cells for periplasmic nuclease activity using DNAse agar plates. As expected, nuclease activity was absent from the plasmid-free parental W3110 strain and the Fab strain (Fig. 1b). Periplasmic routing of nuclease via both the OmpA signal (OSAFab strain) and DsbA signal (DSAFab and DSMFab strains) resulted in nuclease activity. This indicated that translocation of active nuclease to the periplasmic space was achieved by both routes.

Unexpectedly, DNAse agar plate assay data (Fig. 1b) also showed a halo of nuclease activity for strain DSMFab even in the absence of IPTG induction. Suspecting leakiness in the $P_{\text {tac }}$ promoter (Amann et al. 1983), we re-sequenced the $P_{t a c}$ region of the pDSM plasmid and found the promoter sequence to be unchanged. As such no greater degree of leakiness is expected from the DSMFab strain than for the other two nuclease-expressing strains, OSAFab and DSAFab. A possible explanation for this unexpected nuclease activity is that the activity of the Serratial nuclease was significantly higher than that of either Staphylococcal nuclease variant. As such, even if all three nucleases are expressed to the same, basal degree in the absence of IPTG, the small quantity of the Serratial nuclease could still be sufficient to effect observable DNA hydrolysis (Fig. 1b).

All strains grew well in shake-flasks using complex media (Fig. 2a) but defined media revealed growth retardation of the DSMFab strain (Fig. 2b). Previous reports (Ball et al. 1987; Biedermann et al. 1989, 1990; Friedhoff et al. 1994) in which wildtype Serratial nuclease expression was non-lethal to E. coli exclusively used complex media for cell cultivation. Dragosits et al. (2012) indicated that, relative to complex media, growth in defined media increase cell stress in E. coli. This growth retardation in the DSMFab strain suggests combining Serratial nuclease expression with the stress burden of growth in chemically defined media was deleterious to cell growth.

It is commonplace in industrial settings to discontinue cell cultivation procedures if cell growth performance is sub-optimal during the 'seed train' of shake flask cultivation prior to inoculation of bioreactor cultures. In order to focus on industriallyrelevant cultivation environments the DSMFab strain was not taken forward for bioreactor cultivation due to the growth retardation it showed relative to the other strains grown in defined media in shake flasks (Fig. 2b). We continued experimentation with only the Fab, OSAFab and DSAFab strains. These strains were grown to high cell density in a New Brunswick BioFlo 1107.51 bioreactor with variance between strains falling within the $20 \%$ level typical of bioreactor cultivation repeats (Fig. 2c).

Fab' retention improved by swapping

Staphylococcal nuclease translocation signal

Specific yield of intracellular Fab' was lower for the OSAFab strain than the Fab strain, with a difference that widened from $20 \mathrm{~h}$ post-induction onward 
(A)

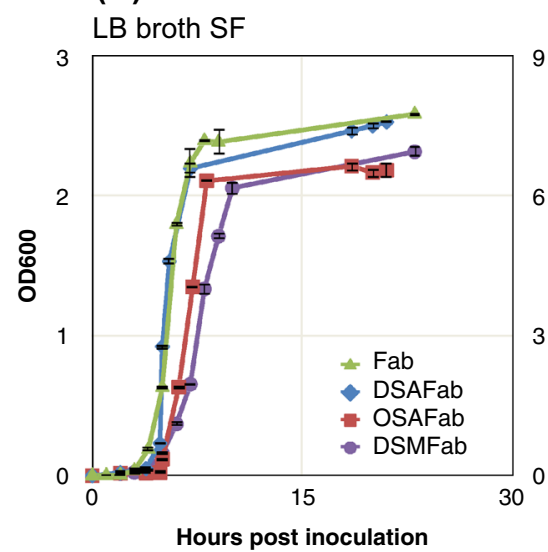

(B) Defined Medium SF

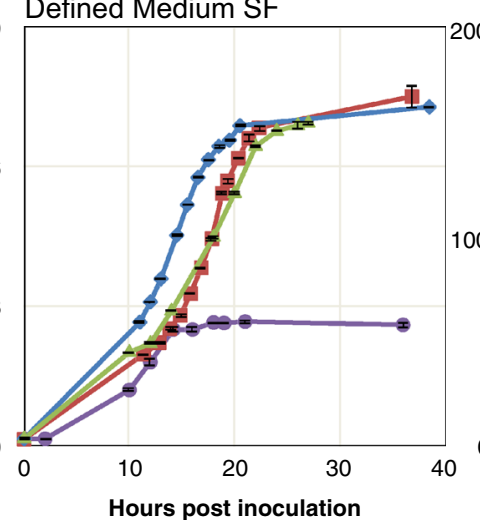

(C) Defined Medium BR

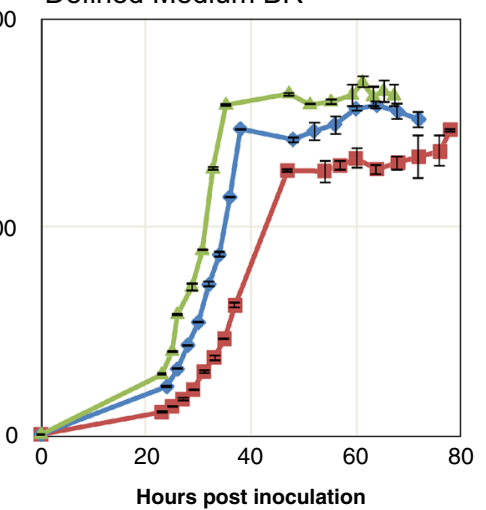

Fig. 2 Growth performance of strains used in this study. Fab', DSMFab, OSAFab and DSAFab strains were used to inoculate: a $200 \mathrm{ml}$ of LB broth in 11 shake flasks (SF) and b $400 \mathrm{ml}$ defined media in 21 shake flasks. $\mathbf{c}$ Failure of DSMFab growth to sufficient cell density meant that only Fab, OSAFab and

(Fig. 3a). In contrast, intracellular Fab' production in the DSAFab strain matched well the Fab' levels achieved by the nuclease-free Fab strain (Fig. 3a). All three strains showed Fab' leakage over the first $20 \mathrm{~h}$ post-induction (Fig. 3b) but at approx. $22 \mathrm{~h}$ postinduction the OSAFab strain showed a steep increase in Fab' leakage to the surrounding growth media. The DSAFab strain showed a Fab' leakage profile similar to the Fab strain, in which no steep increase occurred. Future investigations will be required to ascertain the biomolecular events causing the increased leakage of Fab' from the OSAFab strain compared to the DSAFab and Fab strains.

\section{Conclusions}

Having previously observed that nuclease co-expression coincides with increased Fab' leakage from an E. coli production strain (Nesbeth et al. 2012) we sought here to test the hypothesis that the type of nuclease and signal peptide chosen for nuclease coexpression could also influence Fab' leakage. We considered that testing this hypothesis would be an important first step toward future work to dissect the underlying mechanisms responsible for the leakage.
DSAFab strains were used to inoculate 41 defined media in a New Brunswick BioFlo 1107.51 bioreactor (BR). Optical density measurements were taken at the indicated time points. Key in graph $A$ applies to graphs $B$ and $C$ also. Error bars show standard deviation across two biological repeats

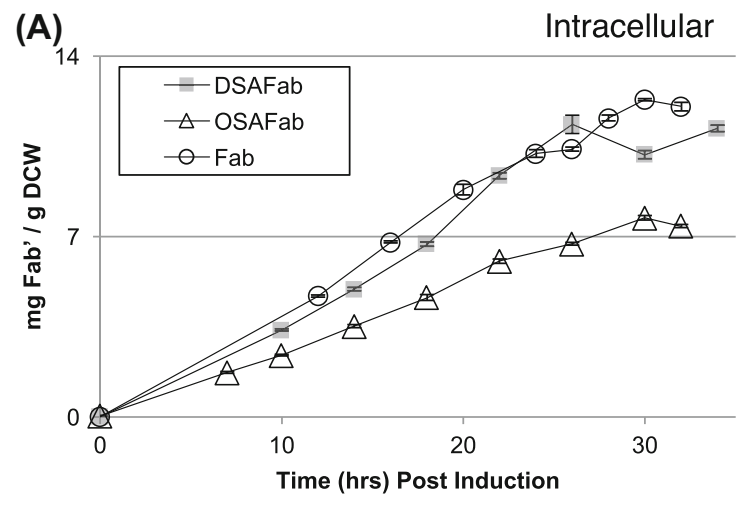

(B)

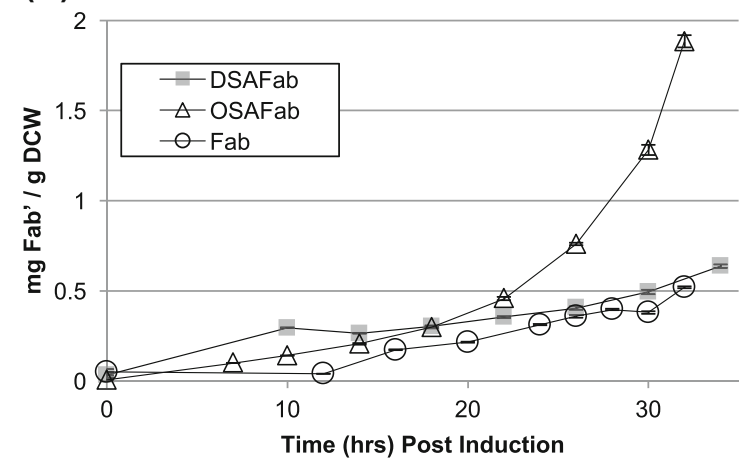

Fig. 3 Fab' fragment production and leakage. a Specific, postinduction, intracellular Fab' levels measured for the Fab, OSAFab and DSAFab strains during bioreactor cultivation. b Specific, post-induction, Fab' levels measured in the growth medium for Fab, OSAFab and DSAFab strains during bioreactor cultivation 
Construction of a plasmid encoding Serratial nuclease with an OmpA signal failed, most likely due to the toxicity of this protein. Secreted bacterial nucleases can provide a competitive advantage to certain bacterial cells by being toxic to other bacteria (Cao et al. 2016). If the OmpA signal is non-functional when attached to Serratial nuclease, this would mean the nuclease is in effect in a mature state within the host E. coli cytoplasm and therefore likely to be cytotoxic by having access to genomic DNA.

Exchanging the OmpA signal to DsbA for the Serratial nuclease resulted in a viable strain, however the strain only grew slowly in chemically defined media. We conclude this slow growth is due to the combination of (i) the increased metabolic burden exerted by defined media relative to complex media and (ii) burdensome effects of a higher level of activity in the ${ }^{\mathrm{DsbA}} \mathrm{SMnuc}$ nuclease, compared to ${ }^{\mathrm{OmpA}}$ nucB and ${ }^{\mathrm{DsbA}}$ nucB, which led to a greater requirement for efficient periplasmic translocation for cell maintenance. Addressing these two pressures retarded cell growth in strain DSMFab, whereas DSAFab and OSAFab strains face only the former pressure of adaptation to defined media so achieved higher growth rates.

For the nuclease strains in this study, DSMFab, DSAFab and OSAFab, the cellular machineries involved in translocation of proteins from the cytosol to the periplasm are likely to be crucial to cell survival, due to the fact that any nucleases allowed to persist in the cytosol would have access to host genomic DNA, the hydrolysis of which would be catastrophic for the cell. DNAse agar plate data (Fig. 1b) were consistent with the DSMFab strain nuclease being more active than the nucleases of the DSAFab and OSAFab strains. Relative to the other strains in this study, the greater activity of the ${ }^{\mathrm{DsbA}}$ SMnuc in the DSMFab strain may exert a greater burden on the host cells with respect the cell maintenance requirement to ensure efficient translocation of the nuclease safely into the periplasmic space. Although this cell maintenance process is energetically affordable when the DSMFab strain is cultivated in complex media, the demands made by cultivation in defined media mean the cells must compromise cell growth in order to preserve cell maintenance, hence the observed growth retardation.

Li et al. (2014) showed that E. coli cultivation in complex versus defined media could have major global impacts on cell metabolism. Component molecules such as amino acids are already present in complex medium such as LB, so cells can simply utilise them directly for protein synthesis. By contrast, defined media such as the one used in this study, and the Defined Non-inducing Broth (DNB) used by Li et al. (2014), contain no amino acids so cells must devote energy to activities such as synthesis of component molecules such as amino acids in addition to polymerisation and folding of macromolecules such as proteins.

Given the observations of Li et al. (2014), and of Dragosits et al. (2012) discussed above, we suggest the different environments complex and defined media provide for $E$. coli cells could be sufficiently distinct that they would favour or inhibit growth in the same E. coli strain. Complex media enables cells to direct energy expenditure on protein production and folding to preserve cell maintenance. Defined media necessitates net diversion of energy away from cell maintenance toward biosynthesis of components such as amino acids.

The periplasm is the principle subcellular structure within didermal bacteria that defines their surface lipidome (Zückert 2014), glycome (Wang et al. 2016), secretome, nutrient uptake (Schalk and Guillon 2013; Sparacino-Watkins et al. 2014) and energy capture (Ishmukhametov et al. 2017). Dynamic control and remodelling of these processes can, therefore, be directly impacted by rates of protein translocation into and across the inner and outer membranes that define the periplasmic space. Directing recombinant proteins to the periplasm is likely to impact the performance of at least a subset of the multiple functions performed by the periplasm. This is frequently found to be the case for industrial strains of $E$. coli engineered to express recombinant periplasmic proteins. For such strains the outer membrane is prone to leak the majority of periplasmic contents to the external milieu during high cell density cultivation (Backlund et al. 2008).

Moving from OmpA to DsbA for the Staphylococcal nuclease rescued periplasmic Fab' retention levels back to those of the original parental strain in which Fab' fragment is expressed alone, with no co-expressed nuclease. We suggest that, in the OSAFab strain, routing three recombinant proteins using the OmpA signal ( ${ }^{O m p A} L C,{ }^{O m p A} H C$ and $\left.{ }^{O m p A} n u c B\right)$ compromised the performance of the SEC trafficking route, a downstream consequence of which was an increased propensity for outward leakage of 
periplasmic contents. Re-routing one of those three recombinant proteins away from the SEC pathway to the SRP pathway ( ${ }^{\mathrm{DsbA}}$ nucB) was able to rescue the performance of the SEC pathway while at the same time preserving the performance of the SRP pathway. Further mechanistic studies will be needed to confirm this hypothesis.

We have shown that, when co-expressing a nuclease and a Fab' fragment, the periplasm translocation route chosen for nuclease transport can be a significant factor in the performance of the strains so this should be considered an important focus of future mechanistic studies. These observations suggest large-scale screening of different nucleases, or variants of a given nuclease, is likely to identify further improvements in strain performance. Future biological investigation will identity which cellular limits, such as metabolic capacity or the carrying capacity of the periplasmic space, result in periplasmic content leakage to the external milieu when exceeded.

Acknowledgements Support from the EPSRC (EP/G034656/1) and BJS Biotechnologies is gratefully acknowledged.

Open Access This article is distributed under the terms of the Creative Commons Attribution 4.0 International License (http:// creativecommons.org/licenses/by/4.0/), which permits unrestricted use, distribution, and reproduction in any medium, provided you give appropriate credit to the original author(s) and the source, provide a link to the Creative Commons license, and indicate if changes were made.

\section{References}

Ahrenholtz I, Lorenz MG, Wackernagel W (1994) A conditional suicide system in Escherichia coli based on the intracellular degradation of DNA. Appl Environ Microbiol 60:3746-3751

Amann E, Brosius J, Ptashne M (1983) Vectors bearing a hybrid trp-lac promoter useful for regulated expression of cloned genes in Escherichia coli. Gene 25:167-178

Avdeeva ON, Myasnikov AG, Sergiev PV, Bogdanov AA, Brimacombe R, Dontsova OA (2002) Construction of the 'minimal' SRP that interacts with the translating ribosome but not with specific membrane receptors in Escherichia coli. FEBS Lett 514:70-73

Backlund E, Reeks D, Markland K, Weir N, Bowering L, Larsson G (2008) Fedbatch design for periplasmic product retention in Escherichia coli. J Biotechnol 135:358-365

Balasundaram B, Nesbeth D, Ward JM, Keshavarz-Moore E, Bracewell DG (2009) Step change in the efficiency of centrifugation through cell engineering: co-expression of Staphylococcal nuclease to reduce the viscosity of the bioprocess feedstock. Biotechnol Bioeng 104:134-142
Ball TK, Saurugger PN, Benedik MJ (1987) The extracellular nuclease gene of Serratia marcescens and its secretion from Escherichia coli. Gene 57:183-192

Bergkessel M, Guthrie C (2013) Colony PCR. Methods Enzymol 529:299-309

Biedermann K, Jepsen PK, Riise E, Svendsen I (1989) Purification and characterization of a Serratia marcescens nuclease produced by Escherichia coli. Carlsberg Res Commun 54:17-27

Biedermann K, Fiedler H, Larsen BS, Riise E, Emborg C, Jepsen PK (1990) Fermentation studies of the secretion of Serratia marcescens nuclease by Escherichia coli. Appl Environ Microbiol 56:1833-1838

Bowering LC, Bracewel DG, Kesharvarz-Moore E, Hoare M, Weir AN (2002) Comparison of techniques for monitoring antibody fragment production in E. coli fermentation cultures. Biotechnol Prog 18:1431-1438

Cao Z, Casabona MG, Kneuper H, Chalmers JD, Palmer T (2016) The type VII secretion system of Staphylococcus aureus secretes a nuclease toxin that targets competitor bacteria. Nat Microbiol 2:16183

Cooke G, Cranenburgh RM, Hanak JA, Ward JM (2003) A modified Escherichia coli protein production strain expressing staphylococcal nuclease, capable of auto-hydrolysing host nucleic acid. J Biotechnol 101:229-239

de Boer HA, Comstock LJ, Vasser M (1983) The tac promoter: a functional hybrid derived from the trp and lac promoters. Proc Natl Acad Sci USA 80:21-25

Dragosits M, Nicklas D, Tagkopoulos I (2012) A synthetic biology approach to self-regulatory recombinant protein production in Escherichia coli. J Biol Eng 6:2

Felinger A, Guiochon G (2001) Validation of a chromatography data analysis software. J Chromatogr A 913:221-231

Friedhoff P, Gimadutdinow O, Rüter T, Wende W, Urbanke C, Thole H, Pingoud A (1994) A procedure for renaturation and purification of the extracellular Serratia marcescens nuclease from genetically engineered Escherichia coli. Protein Expr Purif 5:37-43

Furste JP, Pansegrau W, Frank R, Blocker H, Scholz P, Bagdasarian M, Lanka E (1986) Molecular cloning of the plasmid RP4 primase region in a multi-host-range tacP expression vector. Gene 48:119-131

García-Arrazola R, Dawson P, Buchanan I, Doyle B, Fearn T, Titchener-Hooker N, Baganz F (2005) Evaluation of the effects and interactions of mixing and oxygen transfer on the production of Fab' antibody fragments in Escherichia coli fermentation with gas blending. Bioproc Biosyst Eng 27:365-374

Ishmukhametov RR, DeLeon-Rangel J, Zhu S, Vik SB (2017) Analysis of an N-terminal deletion in subunit a of the Escherichia coli ATP synthase. J Bioenerg Biomembr 49:171-181

Li Q, Wu Y-J (2009) A fluorescent, genetically engineered microorganism that degrades organophosphates and commits suicide when required. Appl Microbiol Biotechnol 82:749-756

Li Q, Aucamp JP, Tang A, Chatel A, Hoare M (2012) Use of focused acoustics for cell disruption to provide ultra scaledown insights of microbial homogenization and its bioprocess impact-recovery of antibody fragments from recombinant E. coli. Biotechnol Bioeng 109:2059-2069 
Li Z, Nimtz M, Rinas U (2014) The metabolic potential of Escherichia coli BL21 in defined and rich medium. Microb Cell Fact 13:45

Lomovskaya O, Totrov M (2005) Vacuuming the periplasm. J Bacteriol 187:1879-1883

Luirink J, Dobberstein B (1994) Mammalian and Escherichia coli signal recognition particles. Mol Microbiol 11:9-13

Movva NR, Nakamura K, Inouye M (1980) Amino acid sequence of the signal peptide of ompA protein, a major outer membrane protein of Escherichia coli. J Biol Chem 10:27-29

Nesbeth DN, Perez-Pardo MA, Ali S, Ward J, Keshavarz-Moore E (2012) Growth and productivity impacts of periplasmic nuclease expression in an Escherichia coli Fab' fragment production strain. Biotechnol Bioeng 109:517-527

Park E, Ménétret JF, Gumbart JC, Ludtke SJ, Li W, Whynot A, Rapoport TA, Akey CW (2014) Structure of the SecY channel during initiation of protein translocation. Nature 506:102-106

Perez-Pardo MA, Ali S, Balasundaram B, Mannall GJ, Baganz F, Bracewell DG (2011) Assessment of the manufacturability of Escherichia coli high cell density fermentations. Biotechnol Prog 27:1488-1496

Pugsley AP (1993) The complete general secretory pathway in gram-negative bacteria. Microbiol Rev 57:50-108

Schalk IJ, Guillon L (2013) Fate of ferrisiderophores after import across bacterial outer membranes: different iron release strategies are observed in the cytoplasm or periplasm depending on the siderophore pathways. Amino Acids 44:1267-1277

Schierle CF, Berkmen M, Huber D, Kumamoto C, Boyd D, Beckwith J (2003) The DsbA signal sequence directs efficient, cotranslational export of passenger proteins to the Escherichia coli periplasm via the signal recognition particle pathway. J Bacteriol 185:5706-5713

Wang Y, Moradali MF, Goudarztalejerdi A, Sims IM, Rehm BH (2016) Biological function of a polysaccharide degrading enzyme in the periplasm. Sci Rep 6:31249

Zückert WR (2014) Secretion of bacterial lipoproteins: through the cytoplasmic membrane, the periplasm and beyond. Biochim Biophys Acta 1843:1509-1516 